\title{
Digital Business Strategy: ToWARd a NeXt GENERATION OF INSIGHTS
}

\author{
Anandhi Bharadwaj \\ Goizueta Business School, Emory University, \\ Atlanta, GA 30332 U.S.A. \{abharad@emory.edu\} \\ Omar A. El Sawy \\ Marshall School of Business, University of Southern California \\ Los Angeles, CA 90089-1421 U.S.A. \{elsawy@marshall.usc.edu\} \\ Paul A. Pavlou \\ Fox School of Business, Temple University, \\ Philadelphia, PA 19122-6083 U.S.A. \{pavlou@temple.edu\}
}

N. Venkatraman

School of Management, Boston University

Boston, MA 02215 U.S.A. \{venkat@bu.edu\}

\begin{abstract}
Over the last three decades, the prevailing view of information technology strategy has been that it is a functional-level strategy that must be aligned with the firm's chosen business strategy. Even within this socalled alignment view, business strategy directed IT strategy. During the last decade, the business infrastructure has become digital with increased interconnections among products, processes, and services. Across many firms spanning different industries and sectors, digital technologies (viewed as combinations of information, computing, communication, and connectivity technologies) are fundamentally transforming business strategies, business processes, firm capabilities, products and services, and key interfirm relationships in extended business networks. Accordingly, we argue that the time is right to rethink the role of IT strategy, from that of a functional-level strategy — aligned but essentially always subordinate to business strategy — to one that reflects a fusion between IT strategy and business strategy. This fusion is herein termed digital business strategy.
\end{abstract}

We identify four key themes to guide our thinking on digital business strategy and help provide a framework to define the next generation of insights. The four themes are (1) the scope of digital business strategy, (2) the scale of digital business strategy, (3) the speed of digital business strategy, and (4) the sources of business value creation and capture in digital business strategy. After elaborating on each of these four themes, we discuss the success metrics and potential performance implications from pursuing a digital business strategy. We also show how the papers in the special issue shed light on digital strategies and offer directions to advance insights and shape future research.

Keywords: Digital business strategy, scope of digital business strategy, scale of digital business strategy, speed of digital business strategy, digital business strategy value creation and capture 


\section{Emergence of Digital Business Strategy}

Over the last three decades, the prevailing view of IT strategy has been that of a functional-level strategy that must be aligned with the firm's chosen business strategy. Even within this so-called alignment view (Henderson and Venkatraman 1993), business strategy directed IT strategy despite calls for recognizing the importance of IT strategy shaping business strategy and transforming business processes and business scope (Venkatraman 1994). This "alignment" thinking of IT strategy as a functional-level strategy — aligned but essentially subordinate to business strategy - has been predominantly reflected in a multitude of research studies, including studies on business process redesign, intrafirm and interfirm systems, business value of IT, and IT outsourcing, among others (e.g., Chan and Reich 2007; Hirschheim and Sabherwal 2001; Hussin et al. 2002; Luftman and Brier 1999; Reich and Benbasat 2000; Sabherwal and Chan 2001; Sabherwal and Kirs 1994; Sledgianowski et al. 2006).

However, during the last decade, impressive improvements in information, communication, and connectivity technologies have unleashed new functionalities. Thus, the post-dotcom decade has seen firms - both established and startups - taking advantage of lower price/performance levels of computing (hardware and software) as well as global connectivity through standard protocols (e.g., Internet and mobile web) to adapt their business infrastructure to the new digital era. These digital technologies are fundamentally reshaping traditional business strategy as modular, distributed, crossfunctional, and global business processes that enable work to be carried out across boundaries of time, distance, and function (e.g., Banker et al. 2006; Ettlie and Pavlou 2006; Kohli and Grover 2008; Rai et al. 2012; Sambamurthy et al. 2003; Straub and Watson 2001; Subramaniam and Venkatraman 2001; Tanriverdi and Venkatraman 2005; Wheeler 2002). Digital technologies also enable different forms of dynamic capabilities suitable for turbulent environments (Pavlou and El Sawy 2006, 2010). Digital technologies are also transforming the structure of social relationships in both the consumer and the enterprise space with social media and social networking (e.g., Susarla and Tan 2012).

Furthermore, products and services increasingly have embedded digital technologies, and it is becoming increasingly more difficult to disentangle digital products and services from their underlying IT infrastructures (e.g., El Sawy 2003; Orlikowski 2009). Digital platforms are enabling cross-boundary industry disruptions, and thus inducing new forms of business strategies (e.g., Burgelman and Grove 2007). In addition, theoretical structures for strategy making in nonlinear dynamic and turbulent environments are also emerging (e.g.,
Davis et al. 2009; Meyer et al. 2005; Pavlou and El Sawy 2010). Finally, exponential advancements in the price/ performance capability of computing, storage, bandwidth, and software applications are driving the next generation of digital technologies to be delivered through cloud computing. It is clearly time to rethink the role of IT strategy, from that of a functional-level strategy-aligned but essentially always subordinate to business strategy - to a fusion between IT strategy and business strategy into an overarching phenomenon we herein term digital business strategy.

Our working definition of digital business strategy is simply that of organizational strategy formulated and executed by leveraging digital resources to create differential value. This working definition highlights (1) going beyond the traditional view, thinking of IT strategy as a function within firms and recognizing the pervasiveness of digital resources in other functional areas such as operations, purchasing, supply chain, and marketing; (2) going beyond systems and technologies, which might have narrowed the traditional views of IT strategy to recognize digital resources, thereby being in line with the resource-based view of strategy (e.g., Barney 1991; Conner and Prahalad 1996; Wernerfelt 1984, 1995); (3) explicitly linking digital business strategy to creating differential business value, thereby elevating the performance implications of IT strategy beyond efficiency and productivity metrics to those that drive competitive advantage and strategic differentiation.

\section{Digital Business Strategy Themes}

We have identified four key themes to guide our future thinking on digital business strategy and provide a framework to help define the next generation of insights. The four themes are (1) the scope of digital business strategy, (2) the scale of digital business strategy, (3) the speed of digital business strategy, and (4) the sources of business value creation and capture in digital business strategy. We believe that the proposed four key themes capture the key attributes of digital business strategy and help us to articulate its main nuances. We synthesize these four key themes with a discussion of success metrics (see Figure 1) that could serve as the starting point for developing a rich set of research questions to guide the debate and discussion within the broader academic community and for guiding practicing managers and executives. ${ }^{1}$ Toward seeking to better understand the nature, role, and emergence of digital business strategy, these four themes have been generated from our own deliberations, inspiration

\footnotetext{
${ }^{1}$ Please note that the key external digital trends and organizational shifts identified in Figure 1 are merely illustrative rather than exhaustive.
} 


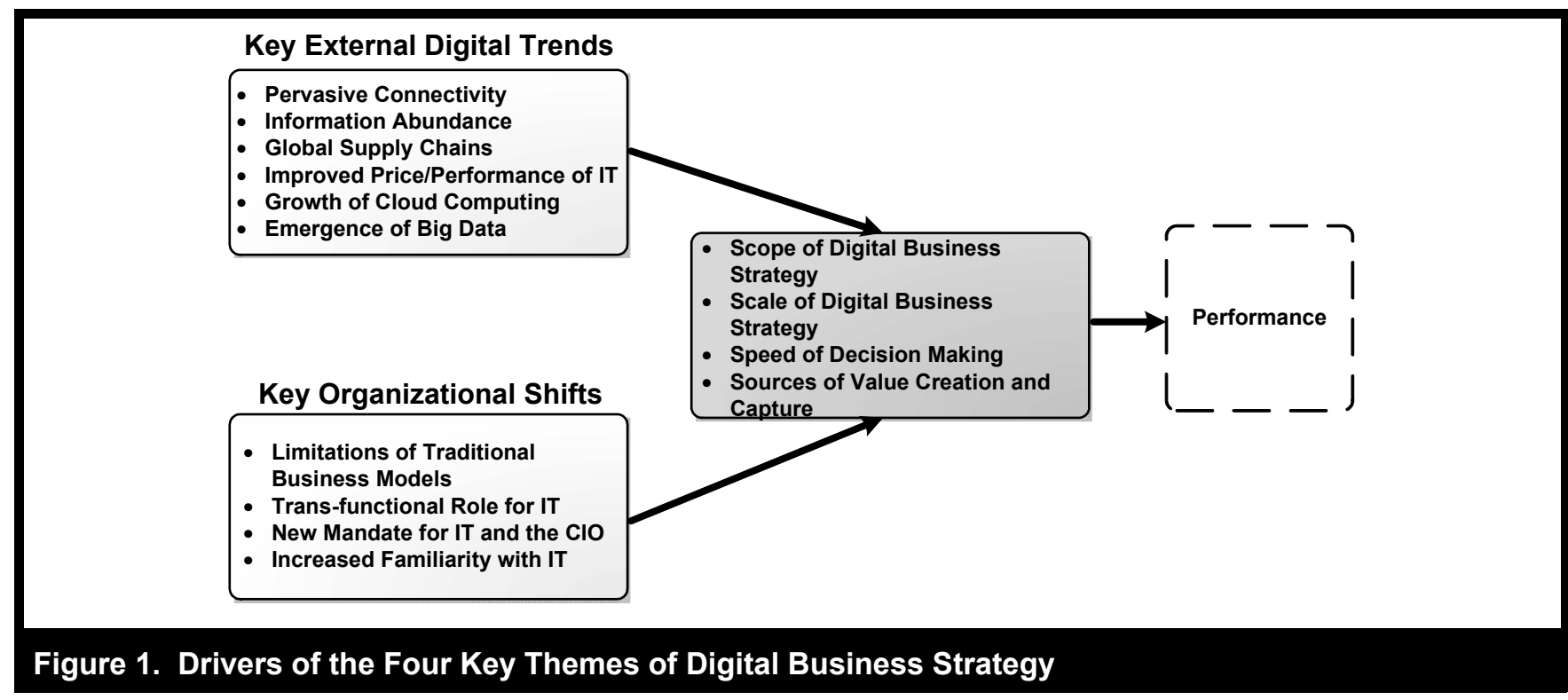

from the paper submissions to this special issue, "Digital Business Strategy: Toward a Next Generation of Insights," and informal conversations with academic and industry thought leaders.

\section{Scope of Digital Business Strategy}

One of the fundamental questions in strategic management relates to corporate scope, which defines the portfolio of products and businesses as well as activities that are carried out within a company's direct control and ownership. Patterns of corporate scope and the logic of diversification have been shown to impact firm performance (e.g., Berger and Ofek 1995; Lang and Stulz 1994; Wade and Hulland 2004), and strategy research has been concerned with how firms optimally use their core competencies and key assets and resources to extend their product and market reach (e.g., Amit and Schoemaker 1993; Barney 1991; Conner and Prahalad 1996; Wernerfelt 1984, 1995).

How can we draw the boundaries of digital business strategy and how can we best characterize its scope? Understanding the scope of digital business strategy helps to conceive its relationship to firms, industries, IT infrastructures, the external environment, and how digital business strategy can be more effective in a variety of settings. Conceptualizing competitive strategy under digital conditions raises the question of how business scope is impacted by digital technologies. We believe that researchers should pay particular attention to how, when, and why the scope of digital business strategy is impacted by digital technologies.

\section{Digital Business Strategy Transcends Traditional Functional and Process Silos}

Digital business strategy is different from traditional IT strategy in the sense that it is much more than a cross-functional strategy, and it transcends traditional functional areas (such as marketing, procurement, logistics, operations, or others) and various IT-enabled business processes (such as order management, customer service, and others). Therefore, digital business strategy can be viewed as being inherently transfunctional. All of the functional and process strategies are encompassed under the umbrella of digital business strategy with digital resources serving as the connective tissue. Digital business strategy relies on rich information exchanges through digital platforms inside and outside organizations that allow multifunctional strategies and processes to be tightly interconnected with the aid of interfirm IT capabilities (e.g., Rai et al. 2012). Discussion of how IT strategy shapes and influences business strategy originally articulated by Henderson and Venkatraman (1993) now emerges to the core through digital business strategy. Accordingly, digital business strategy is broader, more prominent, more embedded, and more encompassing than other functional strategies. Consequently, while IT strategy may be positioned as a functional-level strategy (under the province of the chief information officer), digital business strategy should not be positioned below business strategy but treated as business strategy itself for the digital era. Over time, as firms and industries become more digital and rely on information, communication, and connectivity functionality, we envision that digital business strategy will be the business strategy. At that juncture, there would be no separation between business strategy and digital business strategy. 


\section{Digital Business Strategy Includes Digitization of Products and Services and the Information Around Them}

The formulation of digital business strategy includes the design of products and services and their interoperability with other complementary platforms, and their deployment as products and services by taking advantage of digital resources. Many firms are beginning to see the power of digital resources to create new IT capabilities and craft new strategies around new products and services (e.g., Rai et al. 2012; Ray et al. 2005; Sambamurthy et al. 2003).

Visible examples include Amazon's Web Services on the cloud that substantially expand the strategy of a typical online retailer by encompassing cloud computing services as a key digital resource. Amazon's corporate scope of e-retailing and web services may be considered an unrelated portfolio under traditional strategy conceptualization because of the distance between these two business lines within Amazon. Recognizing and mapping the underlying connections among eretailing, the role of hardware (Kindle) and web services (AWS) requires a more nuanced understanding of the effect of digital technologies than simply computing distances based on SIC-codes and industry classifications. Therefore, Amazon's corporate portfolio may be wrongly characterized as unrelated while we can easily see the related linkages between the constituent parts.

The same logic can be extended to firms such as Google, Netflix, Microsoft, and others as they continue to adjust and fine-tune their corporate scope to take advantage of the developments in hardware, software, and Internet connectivity. Other examples of using novel digital resources to expand the scope of business strategy include Sony's digitized product architecture in game consoles and televisions, Honeywell's and Nest's next-generation thermostats with remote real-time Internet capabilities, GE's healthcare devices that are connected to the Internet to provide remote real-time patient monitoring, and Nike's digitized product development supported by Apple's iOS.

Digital resources around digital business strategy should be viewed relatively broadly. This is because digital resources are "more than just bits and bytes, the digital infrastructure consists of institutions, practices, and protocols that together organize and deliver the increasing power of digital technology to business and society" (Deloitte 2009, p. 2). They include traditional data and information, but they also include the significant explosion of data. The proliferation of social media, cloud computing, and mobile phones has enhanced the quality and quantity of data generated every day. While in the past we have operated under conditions of data (information) scarcity with decisions made with incomplete and often poor quality (even time-lapsed) data, big data create conditions of data (information) abundance due to the massive amount of detailed (and often ready to analyze) data made available. This opens up a whole new portfolio of digital business strategy approaches around the digitization of information for products and services.

The importance of scope for products and services under digital conditions is relevant even beyond technology companies such as Microsoft, Google, and others. It also applies to GE as it seeks to find technology-based extensions in areas such as GE aircraft engines, medical devices, and services as well as transportation systems. It also applies equally well to Nike as it seeks to develop connectivity and informationbased metrics (Nike Fuel) to calibrate the use of its new products. What we need is an updated way to classify and categorize a firm's foray into digital frontiers involving hardware, software, and services rather than treating the distance between physical and digital domains as large and unconnected. Simply put, we need a reconceptualization of the role of digital connections within a firm's corporate portfolio of products and services (its scope) to better prescribe its digital business strategy under increased digital conditions.

\section{Digital Business Strategy Extends the Scope Beyond Firm Boundaries and Supply Chains to Dynamic Ecosystems That Cross Traditional Industry Boundaries}

In a digitally intensive world, firms operate in business ecosystems that are intricately intertwined such that digital business strategy cannot be conceived independently of the business ecosystem, alliances, partnerships, and competitors. Furthermore, the use of digital platforms enables firms to break traditional industry boundaries and to operate in new spaces and niches that were earlier only defined through those digital resources (e.g., D'Adherio 2001; Klein and Rai 2009; Rai et al. 2012; Saraf et al. 2007). Take, for example, how Apple has redefined the mobile entertainment ecosystem, or how Amazon has redefined the book-selling ecosystem. In these two cases, there is no meaningful distinction between business strategy and IT strategy, another example of digital business strategy.

Extending the range and reach of digital business strategy beyond tight supply chains with partners in traditional industries to loosely coupled dynamic ecosystems that are still in emergence is a far more complex undertaking. This requires rethinking how to standardize IT infrastructures and the business processes around them, and it also requires a digital agility to respond to rapidly changing ecosystem conditions. It requires also an orchestration of digital resources that is more multifaceted, data rich, and dynamic. The digital depen- 
dency may require a mindset that may require pooling and sharing digital business strategy with other players in the business ecosystem, whether they are partners or competitors.

\section{Scale of Digital Business Strategy}

How should we think about the scale of digital business strategy under digital conditions? Scale has been a primary driver of profitability in the industrial age. Scale confers benefits of lower unit cost of products and helps enhance profitability. When infrastructure becomes increasingly digital, rather than thinking of scale only in terms of physical factors of production, supply chains, or geographic coverage, we need to think of scale in both physical and digital terms. We have identified at least four ways that scale of digital business strategy is distinct and qualitatively different.

\section{Rapid Digital Scale Up/Down as Strategic Dynamic Capability}

Increased availability and reliance on cloud computing services provides a strategic dynamic capability for firms to scale up or down its infrastructure. A cloud computing infrastructure enables on-demand network access to a shared pool of configurable computing resources. This cloud model is based on on-demand self-service, virtualized resources, rapid and elastic resource utilization, broad network access, and measured quality of service (see http://www.nist.gov/ itl/cloud/). Historically, cloud computing has been seen as the prerogative of the IT function (the CIOs) but increasingly it serves to support supply chains, marketing and service operations, and other functional areas as well (e.g., Buyya et al. 2007). When the digital infrastructure and business strategy are fused, this rapid scaling ability becomes a strategic dynamic capability for the firm to adapt to the dynamic requirements of the digital marketplace. Major cloud service providers such as Amazon Web Services, SalesForce.com, Rackspace, Joyent, Citrix, and VMware tout their pay-as-yougo elastic resources for software, infrastructure, and platforms that allow their customers to dynamically adjust their digital resources as competitive pressures may demand.

\section{Network Effects Within Multisided Platforms Create Rapid Scale Potential}

Network effects exist when the value of a good or a service increases as more consumers use them (examples are e-mail, social media, and buy-sell exchanges) or as more supply-side partners augment the service. As more products and services become digital and connected, network effects become the key differentiator and driver of value creation. While we have seen this theme played out over the last decade in software (Microsoft) and videogames (Sony and Xbox), network effects are becoming key in areas such as mobile hardware and services through the existence of app stores (Apple iOS and Google Android), chipsets, subsidies to handset manufacturers, etc.

As business strategy becomes digital, firms in a wide variety of industries and markets should consider the role of network effects and multisided business models. This can be instantiated on the supply side with digitally interconnected partnerships (such as Google and its partnerships for Androidpowered devices) and on the demand side with interconnections among web pages (such as Facebook with its Open Graph).

We have made significant progress over the last decade focused on network effects and multisided business models focused on software and related areas (e.g., Evans et al. 2008). We believe that these ideas can be extended broadly as digital connections extend to other areas such as automobiles (telematics), retailing through mobile apps, publishing and advertising on tablets, and healthcare.

\section{Scale with Digital Business Strategy Will Increasingly Take Place under Conditions of Information Abundance}

We are not only in a world of ubiquitous digital platforms with broadband networks, cloud computing, and billions of smart end-user devices; we are also in a world of amplified networks with an abundance of data, information, and knowledge. This combination of digital intensity, connectivity, and big data provides a context of networked abundance. This is being further amplified by the growth of what has been called the "Internet of Things" (OECD 2012), which includes not only an interconnection of things, but also an exploding digital network of people and data. Thus scaling with digital business strategy will require understanding how to develop the organizational capabilities to harness the huge quantities of heterogeneous data, information, and knowledge that is generated on a continuous basis. This "big data" includes the explosive chatter on social networks, crowdsourcing of ideas from the edges of networks, and the proliferation of billions of continuous machine-to-machine sensors in areas as diverse as energy, environment, transportation, shipping, and healthcare, to name a few.

\section{Scale Through Alliances and Partnerships}

When digital intensity increases and digital business strategy takes hold, scaling options are more likely to be based on 
alliances and partnerships through shared digital assets with other firms in the business ecosystem across different traditional industry boundaries. While we already see such scaling strategies in settings such as travel and hospitality as they share reservation systems, loyalty programs, and online crossselling (e.g., Star Alliance, OneWorld), we will increasingly see companies rely on different firms to pull together the requisite scale in areas where they do not see competitive advantage. We expect that as firms continue to assess their unique drivers of advantage in digital settings, they would modularize their business processes and rely on plug-and-play capabilities for richly linking digital assets. We already see this with many new startups relying on linkages through application programming interfaces (APIs) and web services.

\section{Speed of Digital Business Strategy}

Although time has been recognized as an important driver of competitive advantage for firms in the strategic management literature for quite some time (e.g., Stalk and Hout 1990), it takes on a more central role in digital business settings. Pervasive connectivity challenges companies to think about time (or more specifically, speed) in important ways. We suggest that speed be thought of through the four dimensions presented below.

\section{Speed of Product Launches}

Digital business strategy accelerates the speed of product launches. Pure-play digital companies such as Facebook, Google, and Amazon appreciate the importance of developing and launching a timed series of products that take advantage of improvements in computer hardware, software, and connectivity. The speed of product launches set by these companies now compels companies that are in the hybrid (digital + physical) space to also accelerate their product introductions. For example, Barnes \& Noble's Nook initiative now has to be aligned with the product launch speed not of the traditional booksellers but of Amazon and Apple. Thus, when traditional firms add digital dimensions to their business strategy, the clock speed of product launches is recalibrated by the speed set by the pure-play companies. Under such conditions, managers across a variety of industries find themselves with capabilities that are misaligned with those of their new competitors.

Steady, predictable improvements in computer hardware functionality (defined by Moore's Law for example) compel firms to develop a multiyear, sequenced product roadmap to remain competitive. We saw this in the case of Apple's multiyear sequenced launch of its iPod over the last decade. More recently, we saw it in the case of iPhone and iPad. And as we combine Moore's Law with steady increases in bandwidth speed and mobile technologies, speed of product launches with connectivity to cloud becomes critical and important.

The speed of product launches in a digital business context also highlights the importance of planned obsolescence. Apple's iPod gives way to the iPod Touch and the iPhone (and even the iPad). The organizational ability to recognize and respond to the fast-paced nature of innovation and implementation with planned obsolescence is fundamental to a firm's competitive success and survival under digital business conditions.

The digital business context, however, brings an added dimension of coordination of product launches across firms in business networks. In traditional business strategy, the speed of launches is largely under the control of a single firm that launches standalone, autonomous products. In recent years, with increased digitization, product launches need to be coordinated in networks with complementary products and services. Amazon's launch of the Kindle Tablet needs to be coordinated with the development of Android OS just as its original Kindle (e-book reader) needed to be timed with an adequate availability of e-books.

\section{Speed of Decision Making}

There is general consensus that technology has allowed firms to speed up decisions that otherwise might be slowed due to information flows up and down the hierarchy through multiple layers of management. Leading companies such as P\&G, GE, and Cisco have invested significantly to provide management with the capability to access diverse streams of information from within the focal firm and extend it to key partners and allies.

Speed as a dimension becomes important in the context of responding to customer service requests in real-time through Twitter, Facebook and other social media platforms. Slowness in response could mean customers moving away from companies perceived as being out of tune with the new reality. Thus, companies across a variety of organizations are experimenting with multifunctional, integrative command centers (e.g., Pepsi's Mission Control for Gatorade and Dell's Social Media Center) to organize information flows from within the company and outside to increase organizational ability to sense and respond faster than ever before.

As noted earlier, big data sets pose enormous challenges to access, process, and analyze the massive amounts of data that accumulate as a natural by-product of routine transactions in a digitally connected world. In simple terms, big data refers 
to data sets with sizes beyond the ability of common software tools to capture, curate, manage, and process the data within a specified elapsed time. As companies make investments to process increased amounts of data, we find that few have made corresponding investments in the organizational processes to drive business value from data and information. Just as in the 1990s with the wave of business process redesign efforts, the value lies not in investing in technology but in how increased access to information drives faster and more effective decisions.

\section{The Speed of Supply Chain Orchestration}

End-to-end visibility and ERP deployments have allowed companies to be more efficient than before thanks to developments in software from companies such as SAP and Oracle. This, coupled with outsourcing of non-core activities to a network of partners, has allowed companies to optimize their supply chains in extended interfirm networks and enhance efficiency (e.g., Klein and Rai 2009; Rai et al. 2012; Saraf et al. 2007). The best in class in consumer electronics today are not traditional electronics companies such as Sony or Panasonic but Apple, which has achieved 74 inventoryturns in a year (average of 5 days of inventory in the supply chain) - supposedly at least twice faster than the industry average. Therefore, in industries marked by fast changes in technology functionality, competitive advantage lies not in just announcing new products (first-mover advantage) but in ensuring the availability of new products on a global basis to capture the fast-mover advantage.

The speed of supply chain orchestration on a global basis is now becoming an important driver of competitive advantage. This is more than outsourcing of non-value activities, it is truly working in a collaborative fashion from conceptual design to recycling of the products. Orchestration of supply chain is not about managing today's product portfolio but also innovating tomorrow's product portfolio, which necessitates the need for dynamic realignment of partners and suppliers. This brings us to the final dimension of speed about the pace of network formation and adaptation.

\section{Speed of Network Formation and Adaptation}

The pace of network formation is rapidly accelerating in every firm, industry sector, and industry (e.g., Easley and Kleinberg 2010; Venkatraman and Lee 2004; Viswanathan 2005). One of the key requirements of digital business strategy is new organizational capability to design, structure, and manage networks that provide complementary capabilities to what firms have inside their own hierarchies. Digital business ecosystems in areas such as mobile apps provide useful insights into the new strategic capability of orchestrating networks. The speed of network formation is faster than traditional supply chains in areas such as automotive, chemicals, or textiles where trust built up over long periods of time acts as the glue. In contrast, app developers align and realign their affinity to the different platforms based on technical functionality and attractiveness. The dynamics of network formation and reformation in such areas raise implications for us to rethink the drivers of network structure in digital settings.

\section{Sources of Value Creation and Capture}

Value creation and capture in traditional business models are relatively well understood and strategic management theories and practice have developed robust rules focused on leveraging physical, tangible resources. Digital business strategy brings in additional dimensions that alter the nature of value creation and capture. We discuss them below.

\section{Increased Value from Information}

While information-based businesses have existed for a long time (e.g., newspapers and magazines) in physical forms, the digital business context brings new opportunities to create value from information. As magazines abandon their physical formats (e.g., Newsweek), they need to fundamentally rethink their unique source of value through curating content and assess the balance between subscription and advertising. Google, Facebook, and eBay are just few examples of new value created from information that go beyond niche areas such as financial services whose business models rely on accurate, timely information. Moreover, many firms are able to fine-tune their actions and personalize their offerings based on information about customer preferences through Facebook, Twitter, and others. In addition, many business models based in information have emerged in areas such as healthcare and energy.

Digital business strategy has also made possible the democratization of content as well as the subsequent sharing, remixing, redistribution, and resyndication of content in newer and more useful forms. These transformations have caused dramatic power shifts in market channels and disintermediations that disrupt traditional sources of economic profits while creating fundamentally new sources of value.

\section{Value Creation from Multisided Business Models}

Digital business strategy brings into sharp focus the importance of multisided revenue models not just in software. Going beyond software pricing such as Adobe Reader and 
browsers, we now find that a wide range of companies are examining multisided business models. Indeed, new leaders in the digital space (e.g., Google, Facebook, Twitter, and others) base their raison d'être on such models. These multisided business models are also multilayered where a company gives away certain products or services in one layer to capture value at a different layer. For example, Google's entry into mobile phones is based on giving away the software (Android) free and monetizing it through its ability to influence and control advertising. Digital business strategy introduces more nuanced ways to conceptualize the drivers of value creation and capture by thinking about the multisided nature of interactions.

\section{Value Capture through Coordinated Business Models in Networks}

The logical extension of multisided business models is a recognition that value creation and capture in digital settings often involve complex and dynamic coordination across multiple companies. In the case of videogames, console manufacturers, game developers, publishing, and other content owners coordinate and time their respective offerings to be able to cocreate value in networks and share their respective pieces of value.

Specifically, in the case of mobile ecosystems, the value capture involves complex coordination between app developers, the mobile OS (Apple, Android, Windows, or Blackberry), hardware manufacturers, telecom operators, and service providers such as Facebook, YouTube, and others. The complicating factor is that the business models are not independent but intersect and interoperate across these different players. So, we need richer models that delineate interdependent ecosystems that evolve more rapidly than what we have seen in traditional settings.

\section{Value Appropriation through Control of Digital Industry Architecture}

Apple has a smaller market share but leads in profit share in the mobile industry because it earns its profits not only through its product (iPhone and $\mathrm{iOS}$ ) but receives a share of the follow-on revenue that the telecom carriers earn from the end users. Unlike other handset manufacturers, such as Samsung and HTC, Apple's appeal to the end consumer is arguably higher. This control of the industry architecture allows Apple to extract a higher premium. Is Apple's place in the telecom industry an outlier or an early indication of how we could see more companies that redefine industry architecture with digital control points and extract a disproportionate share of profit? We need to think more about the role of digital technologies in influencing not only the business strategies of individual firms but also the nature of the industry and the sources of value creation and location of value capture. In doing so, we will be in a better position to identify the key metrics that should be tracked and followed in different industries.

Table 1 summarizes the description of these key themes of digital business strategy with an eye toward performance by introducing some important questions on each of the four themes to help formulate and execute organizational strategy by leveraging digital resources to create differential value.

\section{Papers in the Special Issue on Digital Business Strategy}

The papers in this special issue on digital business strategy offer some valuable insights on the key themes we have developed in this paper. Collectively, the papers speak to the expanded scope and scale of digital business strategy as well as to the novel use of digital resources to rapidly formulate and execute digital business strategy to create differential business value. The papers in this issue include six standalone research papers and a collection of "Issues and Opinions" pieces, grouped under the title "Visions and Voices on Emerging Challenges in Digital Business Strategy." The opinion pieces are written by thought leaders who, in addition to their scholarship, have a keen sense of practice.

The six research papers collectively examine the convergence of the information systems and strategy domains under the umbrella of digital business strategy. The papers focus on digital business strategy within and outside the enterprise, including the firm's competitive industry environment and its customer connections as determinants of digital business strategy. The papers also examine how to formulate and execute digital business strategy as well as examining business models for digital products.

First, echoing the core theme of this special issue, and focusing on the rapid convergence of the information systems and strategy domains, the article by Paul Drnevich and David Croson, titled "Information Technology and Business-Level Strategy: Toward an Integrated Theoretical Perspective," makes a persuasive case for why digital business strategy matters to business success. In developing an integrated theoretical perspective, the authors use a framework of potential profit mechanisms to show how investments in digital resources and capabilities enable dynamic capabilities, such as the flexibility to focus on rapidly changing opportunities or to quickly abandon losing initiatives. 


\section{Table 1. Key Questions on Digital Business Strategy Themes}

\section{Scope of Digital Business Strategy}

- What is the extent of fusion and integration between IT strategy and business strategy?

- How encompassing is digital business strategy, and how effectively does digital business strategy transcend traditional functional and process silos?

- How well does digital business strategy exploit the digitization of products and services, and the information around them?

- How well does digital business strategy exploit the extended business ecosystem?

\section{Scale of Digital Business Strategy}

- How rapidly and cost effectively can the IT infrastructure scale up and down to enable a firm's digital business strategy to bolster a strategic dynamic capability?

- How well does digital business strategy leverage network effects and multisided platforms?

- How well does digital business strategy take advantage of data, information, and knowledge abundance?

- How effective is digital business strategy in scaling volume through alliances and partnerships?

Speed of Digital Business Strategy

- How effective is digital business strategy in accelerating new product launches?

- How effective is digital business strategy in speeding up learning for improving strategic and operational decision making?

- How effectively does digital business strategy bolster the speed of dynamic supply chain orchestration?

- How quickly does digital business strategy enable the formation of new business networks that provide complementary capabilities?

- How effectively does the digital business strategy speed up the sense and respond cycle?

\section{Sources of Value Creation and Capture}

- How effective is digital business strategy in leveraging value from information?

- How effective is digital business strategy in leveraging value from multisided business models?

- How effective is digital business strategy in capturing value through coordinated business models in networks?

- How effective is digital business strategy in appropriating value through the control of the firm's digital architecture?

Next, the article by Sunil Mithas, Ali Tafti, and Will Mitchell, titled "How a Firm's Competitive Environment and Digital Strategic Posture Influence Digital Business Strategy," examines the competitive industry environment as a fundamental component of digital business strategy that must be accounted for when formulating the firm's strategic posture. The paper examines how the industry's competitive environment shapes the way that a firm's digital strategic posture (the degree of engagement in a particular class of digital business practices relative to the industry norm) affects the firm's realized digital business strategy. The results imply that digital business strategy is not only a matter of internally optimizing the firm's operations or of externally responding to competitors, but that it also arises from a deep awareness and dynamic responsiveness to the competitive environment.

Similarly, Jason Woodard, Narayan Ramasubbu, Ted Tschang, and Vallabh Sambamurthy in their paper, titled "Design Capital and Design Moves: The Logic of Digital Business Strategy," study digital options and design moves as digital resources that help the formulation and execution of digital business strategy. They conceptualize the logic of digital business strategy in terms of design capital (the cumulative stock of designs of digital artifacts that are owned or controlled by a firm), and design moves (the discrete strategic actions that enlarge, reduce, or modify a firm's design stock) and highlight the interplay between these constructs to show how the design of digital artifacts contributes to firm-level business value creation and capture. They show how enterprises that hold positions of strategic value (i.e., hold many control points) in these digitally enabled networks exercise control as technology triggers new dynamic cycles of value creation opportunities.

Panjak Setia, Viswanath Venkatesh, and Supreet Joglekar take a customer-centric view of digital business strategy in their article, "Leveraging Digital Technologies: How Information Quality Leads to Localized Capabilities and Customer Service Performance." Through survey data from a large bank, they show how information quality acts as a key digital resource and a critical antecedent to customer-side dynamic capabilities that enable a rapid sense-and-respond to customer needs. This study provides insights for how local business processes and digital design can influence an enterprise's customer-side response capabilities and digital business strategy.

Focusing on the specific context of online music, the paper by Gal Oestreicher-Singer and Lior Zalmanson, titled "Content or Community? A Digital Business Strategy for Content Providers in the Social Age," views the digital community formed by music websites through network effects to act as 
the driving force for consumers to pay a premium for music. Essentially, the digitally connected "prosumer" acts as a resource for the firm to create value for other consumers. In doing so, they address the changes wrought by social computing and the fusion between content and community in digital spaces. The paper shows how digital business models can remain viable in a world of "freemium" and provides direct and compelling evidence of the importance of fusing social computing with content delivery to create and capture new sources of business value in today's digital environments within the domain of digital business strategy.

Finally, the article by Margherita Pagani, titled "Digital Business Strategy and Value Creation: Framing the Dynamic Cycle of Control Points," uses a novel view of digitally enabled value networks as configurations of control points through which enterprises in digital business ecosystems create and capture value. Through empirical evidence from the European and U.S. broadcasting industries, the study shows how these control point constellations shift as technological innovation and cross-boundary disruptions trigger new dynamic cycles of value creation opportunities. The enterprises that hold many control points have a strategic advantage in terms of how the value network operates and how value is appropriated - and how the shift in those control points influences the dynamic execution of digital business strategy.

The "Issues and Opinions" pieces take bolder and more avantgarde positions on various issues related to digital business strategy. These pieces are presented as a collection in an article titled "Visions and Voices on Emerging Challenges in Digital Business Strategy" and we have provided a separate integrative commentary by way of introducing these pieces and their contribution to thought leadership as well as practice. The five pieces are "Leadership in a Digital World: Embracing Transparency and Adaptive Capacity" authored by Warren Bennis, "Transparency Strategy: Competing with Information in a Digital World" authored by Nelson Granados and Alok Gupta, "Revealing Your Hand: Caveats in Implementing Digital Business Strategy" authored by Varun Grover and Rajiv Kohli, "Value Architectures for Digital Business: Beyond the Business Model" authored by Peter Keen and Ronald Williams, and "Commoditized Digital Processes and Business Community Platforms: New Opportunities and Challenges for Digital Business Strategy" authored by Lynne Markus and Claudia Loebbecke.

\section{The Platform Forward}

Ideas regarding digital business strategy are still in the early stages of development. Many firms continue to treat different facets of digital shifts within traditional domains, such as marketing, operations, information systems, and Internet technologies. Such disjointed views of digital shifts have provided limited benefits to firms as they are still straddling the continuum between the physical to the digital. Some firms have embarked on social media as part of their marketing operations, but without necessarily linking them back to their core IT infrastructure. Other firms have focused on streamlining supply chains without necessarily taking an endto-end look at the coordination challenges and rapid scale-up necessary to buffer against uncertainties in the environment. The main thesis of both our paper and the overall special issue on "Digital Business Strategy: Toward a New Generation of Insights" is that the time is right to shift our thinking about IT, not as a functional-level response, but as a fundamental driver of business value creation and capture. Digital technologies shape the new business infrastructure and influence the new organizational logic and patterns of coordination within and across firms.

Nonetheless, we believe that the four themes we have outlined lend themselves to specific intermediate metrics to be tracked and assessed. We are not at a stage of either theoretical development or management practice to offer generic metrics of firm performance from an effective digital business strategy. However, we urge researchers examining the impacts of digital business strategy to theorize and develop metrics reflecting the four themes introduced here.

For example, what metrics could suitably describe the role of digital technologies on changing business scope both inside a company (corporate scope) and in an ecosystem (a company's network scope)? The distinguishing characteristic of the scope of various digital business strategies is that it is not about a single firm's corporate scope but that it also extends to the interconnections within a network of firms. How should we conceptualize and measure such ideas in rich theoretical terms? Similarly, constructs and measures of the scale of digital business strategy should reflect the nature of scale through alliances and partnerships as well as in dynamically adjusting the requisite scale as a management capability. What are the drivers of virtual scale, and under what conditions are they more effective than scale through ownership?

In terms of the speed of decision making, we caution that this is not to be conceptualized in absolute terms but relative to the speed of the market and the competitive environment. What characterizes digital business strategies whose clockspeed of decisions and actions are aligned with the clockspeed of market conditions from those firms that have mismatched speeds? What technology characteristics create the conditions for enhanced clock-speed of decisions? In line with other two themes, speed also recognizes the importance 
of network: speed of coordination of product launches with others in the ecosystem that complement the value of products as well as dynamic adjustment to the number and diversity of partners.

Finally, we believe that advances in our thinking about digital business strategy would occur as we articulate the shifts in sources of value creation through digital resources and the location of value capture in digital business networks and ecosystems. In this paper, we have adopted a general view of digital business strategy arising from the resource-based view and the dynamic capabilities perspective. Just as strategic management researchers have refined the general ideas of the resource-based view and dynamic capabilities over the last two decades, we expect that we would have a more refined and detailed understanding of digital resources and their role in impacting value creation, capture, and distribution of business value among partner firms in emerging industry ecosystems.

We hope that this collection of papers will provoke IS researchers and strategic management researchers to step up their collaborative efforts and will provide an energizing platform to help produce the next generation of insights around digital business strategy. It is a very exciting area whose time has come. The future of digital business strategy is already here, it is just unevenly distributed!

\section{References}

Amit, R., and Schoemaker, P. 1993. "Strategic Assets and Organizational Rent," Strategic Management Journal (14:1), pp. 33-46.

Banker, R. D., Bardhan, I. R., Chang, H., and Lin, S. 2006. "Plant Information Systems, Manufacturing Capabilities, and Plant Performance," MIS Quarterly (30:2), pp. 315-337.

Banker, R., Hu, N., Pavlou, P. A., and Luftman, J. 2011. "Strategic Positioning, CIO Reporting Structure, and Firm Performance," MIS Quarterly (35:2), pp. 487-504.

Barney J. B. 1991. "Firm Resources and Sustained Competitive Advantage," Journal of Management (17:1), pp. 99-120.

Berger, P., and Ofek, E. 1995. "Diversification's Effect on Firm Value," Journal of Financial Economics (37:1), pp. 39-65.

Bharadwaj, A., El Sawy, O. A., Pavlou, P. A., and Venkatraman, V. 2013. "Visions and Voices on Emerging Challenges in Digital Business Strategy," MIS Quarterly (37:2), pp. 633-661.

Burgelman, R. A., and Grove, A. 2007. "Cross-Boundary Disruptors: Powerful Inter-Industry Entrepreneurial Change Agents," Strategic Entrepreneurship Journal (1:3-4), pp. 315-327.

Buyya, R., Broberg, J., and Goscinski, A. (eds.). 2011. Cloud Computing: Principles and Paradigms, New York: Wiley Press.

Chan, Y. E., and Reich, B. H. 2007. "IT Alignment: What Have We Learned?," Journal of Information Technology (22), pp. 297-315.
Conner, K. R., and Prahalad, C. K. 1996. "A Resource-Based Theory of the Firm: Knowledge Versus Opportunism," Organization Science (7:5), pp. 477-501.

D'Adderio, L. 2001. "Crafting the Virtual Prototype: How Firms Integrate Knowledge and Capabilities Across Organisational Boundaries," Research Policy (30:9), pp. 1409-1424.

Davis, J. P., Eisenhardt, K. M., and Bingham, C. B. 2009. "Optimal Structure, Market Dynamism, and the Structure of Simple Rules," Administrative Science Quarterly (54:3), pp. 413-452.

Deloitte. 2009. "Measuring the Forces of Long Term Change: The 2009 Shift Index," (http://www.deloitte.com/assets/DcomUnitedStates/Local\%20Assets/Documents/us_tmt_ce_Shift Index 072109ecm.pdf).

Drnevich, P. L., and Croson, D. C. 2013. "Information Technology and Business-Level Strategy: Toward an Integrated Theoretical Perspective," MIS Quarterly (37:2), pp. 483-509.

Easley, D., and Kleinberg, J. 2010. Networks, Crowds, and Markets: Reasoning About a Highly Connected World, Cambridge, UK: Cambridge University Press.

El Sawy, O. A. 2003. "The IS Core IX: The 3 Faces of Information Systems Identity: Connection, Immersion, and Fusion," Communications of the AIS (12), Article 39, pp. 588-598.

Ettlie, J., and Pavlou, P. A. 2006. "Technology-Based New Product Development Partnerships," Decision Sciences (37:2), pp. 117-148.

Evans, D. S., Hagiu, A., and Schmalensee, R. 2008. Invisible Engines: How Software Platforms Drive Innovation and Transform Industries, Cambridge, MA: MIT Press.

Henderson, J. C., and Venkatraman, N. 1993. "Strategic Alignment: Leveraging Information Technology for Transforming Organizations," IBM Systems Journal (32:1), pp. 4-16.

Hirschheim, R., and Sabherwal, R. 2001. "Detours in the Path toward Strategic Information Systems Alignment," California Management Review (44:1), pp. 87-108.

Hussin, H., King, M., and Cragg, P. 2002. "IT Alignment in Small Firms," European Journal of Information Systems (11:2), pp. 108-127.

Klein, R., and Rai, A. 2009. "Interfirm Strategic Information Flows in Logistics Supply Chain Relationships," MIS Quarterly (33:4), pp. 735-762.

Kohli, R., and Grover, V. 2008. "Business Value of IT: An Essay on Expanding Research Directions to Keep up with the Times," Journal of the Association for Information Systems (9:1), pp. 23-39.

Lang, L. H. P., and Stulz, R. M. 1994. “Tobin's q, Diversification and Firm Performance." Journal of Political Economy (102), pp. 1248-1280.

Luftman, J., and Brier, T. 1999. "Achieving and Sustaining Business-IT Alignment," California Management Review (42:1), pp. 109-112.

Meyer, A. D., Gaba, V., and Calwell, K. A. 2005. “Organizing Far from Equilibrium: Nonlinear Change in Organizational Fields," Organization Science (16:5), pp. 456-473.

Mithas, S., Tafti, A. and Mitchell, W. 2013. "How a Firm's Competitive Environment and Digital Strategic Posture Influence Digital Business Strategy," MIS Quarterly (37:2), pp. 511-536. 
OECD. 2012. "Machine-to-Machine Communications: Connecting Billions of Devices," OECD Digital Economy Papers, No. 192, OECD Publishing (http://www.oecd-ilibrary.org/science-andtechnology/machine-to-machine-communications_5k9gsh2gp0 43-en).

Orlikowski, W. 2009. "The Sociomateriality of Organisational Life: Considering Technology in Management Research," Cambridge Journal of Economics (34), pp. 125-141.

Oestreicher-Singer, G., and Zalmanson, L. 2013. "Content or Community? A Digital Business Strategy for Content Providers in the Social Age," MIS Quarterly (37:2), pp. 591-616.

Pagani, M. 2013. "Digital Business Strategy and Value Creation: Framing the Dynamic Cycle of Control Points," MIS Quarterly (37:2), pp. 617-632.

Pavlou, P. A., and El Sawy, O. A. 2006. "From IT Leveraging Competence to Competitive Advantage in Turbulent Environments," Information Systems Research (17:3), pp. 198-227.

Pavlou, P. A., and El Sawy, O. A. 2010. "The 'Third Hand': IT-Enabled Competitive Advantage in Turbulence through Improvisational Capabilities," Information Systems Research (21:3), pp. 443-471.

Rai, A., Pavlou, P. A., Im, G., and Du, S. 2012. "Interfirm IT Capability Profiles and Communications for Cocreating Relational Value: Evidence from the Logistics Industry," MIS Quarterly (36:1), pp. 233-262.

Ray, G., Muhana, W. A., and Barney, J. B. 2005. "Information Technology and the Performance of the Customer Service Process: A Resource-Based Analysis," MIS Quarterly (29:4), pp. 625-642.

Reich, B. H., and Benbasat, I. 2000. "Factors That Influence the Social Dimensions of Alignment Between Business and Information Technology Objectives," MIS Quarterly (24:1), pp. 81-114.

Sabherwal, R., and Chan, Y. 2001. "Alignment Between Business and IS Strategies: A Study of Prospectors, Analyzers, and Defenders," Information Systems Research (12:1), pp. 11-33.

Sabherwal, R., and Kirs, P. 1994. "The Alignment Between Organizational Critical Success Factors and Information Technology Capability in Academic Institutions," Decision Sciences (25), pp. 301-301.

Sambamurthy, V., Bharadwaj, A., and Grover, V. 2003. "Shaping Agility Through Digital Options: Reconceptualizing the Role of Information Technology in Contemporary Firms," MIS Quarterly (27:2), pp. 237-263.

Saraf, N., Langdon, C., and Gosain, S. 2007. "IS Application Capabilities and Relational Value in Interfirm Partnerships," Information Systems Research (18:3), pp. 320-339.

Setia, P., Venkatesh, V., and Joglekar, S. 2013. "Leveraging Digital Technologies: How Information Quality Leads to Localized
Capabilities and Customer Service Performance," MIS Quarterly (37:2), pp. 565-590.

Sledgianowski, D., Luftman, J., and Reilly, R. R. 2006. "Development and Validation of an Instrument to Measure Maturity of IT Business Strategic Alignment Mechanisms," Information Resources Management (19:3), pp. 18-33.

Stalk, G., and Hout, T. M. 1990. Competing Against Time: How Time-Based Competition Is Reshaping Global Markets, New York: Free Press.

Straub, D., and Watson, R. 2001. "Transformational Issues in Researching IS and Net-Enabled Organizations," Information Systems Research (12:4), pp. 337-345.

Subramaniam, M., and Venkatraman, N. 2001. "Determinants of Transnational New Product Development Capability: Testing the Influence of Transferring and Deploying Tacit Overseas Knowledge," Strategic Management Journal (22:4), pp. 359-378.

Susarla, A., Oh, J-H., and Tan, Y. 2012. "Social Networks and the Diffusion of User-Generated Content: Evidence from YouTube," Information Systems Research (23:1), pp. 123-141.

Tanriverdi, H., and Venkatraman N. 2005. "Knowledge Relatedness and the Performance of Multibusiness Firms," Strategic Management Journal (26:2), pp. 97-11.

Venkatraman, N. 1994. "IT-Enabled Business Transformation: From Automation to Business Scope Redefinition," Sloan Management Review (35:2), pp. 73-87.

Venkatraman, N., and Lee, C-H. 2004. "Preferential Linkage and Network Evolution: A Conceptual Model and Empirical Test in the U.S. Video Game Sector," Academy of Management Journal, (47:6), pp. 876-892.

Viswanathan, S. 2005. "Competing Across TechnologyDifferentiated Channels: The Impact of Network Externalities and Switching Costs," Management Science (51:3), 2005, pp. 483-496.

Wade, M., and Hulland, J. 2004. "Review: The Resource-Based View and Information Systems Research: Review, Extension, and Suggestions for Future Research," MIS Quarterly (28:1), pp. 107-142.

Wernerfelt, B. 1984. "A Resource-Based View of the Firm," Strategic Management Journal (52), pp. 171-180.

Wernerfelt, B. 1995. "The Resource-Based View of the Firm: Ten Years After," Strategic Management Journal (16:3), pp. 171-174.

Wheeler, B. C. 2002. "NEBIC: A Dynamic Capabilities Theory for Assessing Net-Enablement," Information Systems Research (13:2), pp. 125-146.

Woodard, C. J., Ramasubbu, N., Tschang, F. T., and Sambamurthy, V. 2013. "Design Capital and Design Moves: The Logic of Digital Business Strategy,” MIS Quarterly (37:2), pp. 537-564. 